\title{
Preparation and Properties of Urea Slow Release Coated with Potassium Humate, Bentonite and Polyacrylamide as Compositely Fertilizer which Reflected on the Productivity of Wheat Crop Wagida Z. Hassan Soil, Water and Environ. Res. Inst., Agric. Res. Center, Giza, Egypt
}

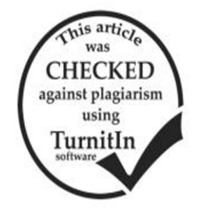

ABSTRACT

A slow release of urea fertilizer has become a necessity since it reduces the loss of nitrogen. This can be achieved by using different types of coatings, like sulfur, starch and wax etc. In this study, the producing of urea coated with bentonite, polyacrylamide and potassium humate which working on the reduction of nitrogen loss as resultant of either leaching or valorization and minimize environmental pollution beside reduce the consumption of fertilizer. Also, improve soil chemical properties, its positive impact on the productivity of wheat crop, and total content of macronutrients. Lab experiments were performed to determine the best concentration of bentonite to coated urea such as percent coating which showed that percent coating was increased with increasing the concentration of bentonite. The dissolution rate was decreased with concentration of bentonite $(2.5 \%)$ in combination with $0.1 \%$ polyacrylamide. Along with, the experiment of investigation of the water absorption showed the greater absorbency of water was shown at 2 and $2.5 \%$ bentonite. In addition to, the incubation experiment revealed that amount released from nitrogen at 10 and 15 days were greater, which lasted for up to 20 days in urea uncoated than urea- coated. The concentration of $2.5 \%$ of bentonite seems to be favorable than other concentrations. These experiments conformed that the suitable quantity used in the coating urea by bentonite and polyacrylamide. Through an infrared (FTIR) diagnosis of the urea coated, its properties were identified at different wavelengths. The functional groups such as phenol, carboxyl, etc. which affect the compound's effectiveness when the urea associates with bentonite, polyacrylamide and potassium humate as one compound. Concerning, trial experiment were laid out at El- Ismailia Agriculture Research Station Farm, Agric. Res. Center (ARC), Egypt. At two successive seasons who's planted with wheat crop (Triticum aestivum L., CV. Giza 168) in a sandy soil under sprinkler irrigation system. To evaluate urea's coated beneficial effect on soil along with plant productivity. Established by the following transactions three rates of nitrogen 100, 75 and 50\% from recommended dose of uncoated urea, urea formaldehyde and urea coated. Results show that, mean values of soil $\mathrm{pH}$ were decreased with urea formaldehyde and urea coated compared to uncoated urea (control), this inversely with values of EC in soil where increased with coated urea compare to other treatments in two seasons . Data revealed an increases of N,P and K availability in soil under impact of coated urea and urea form compared to control (uncoated urea) treatments with consideration that urea coated was superior than urea form. Regarding the plant behavior, results revealed that the mean values of the biological yield, grains and straw of wheat crop under impact of coated urea and urea formaldehyde treatments were increases compared to uncoated urea in two seasons. But it was observed that this increase was better when applying urea coated. Finally, this product is a good controlled $\mathrm{N}$ release of nitrogen and water absorption, as well as degradable in soil and environment friendly, which reflected on the plant productivity along with it's could be useful in agricultural.

Keywords: urea coated; bentonite; polyacrylamide; potassium humate; soil properties; wheat productivity

\section{INTRODUCTION}

Agriculture is the lifeblood of both old and new so humans must in innovate and overcome the difficulties that may face us during agriculture. Therefore, idea of this research where we have a problem in fertilization, either high price of fertilizer or loss by surface run off with rain or irrigation water, leaching and vaporization especially nitrogen fertilizers. Slow release fertilizers are one of the means of min imizing the fertilizer loss. This can be achieved by using different types of coating, in this research we want to encase urea that overcomes uses urea coated with clay mineral and polyacrylamide which return urea a good production for agriculture.

Urea is one of the most widely used N-fertilizers. The main problem of urea application on farmlands is its low efficiency; about $30-40 \%$ of its nitrogen can be absorbed by plants, some of its nitrogen loss through $\mathrm{NH}_{3}$ volatilization (20-53\%) and losses through other ways can reach $60 \%$ (Nuryani et al., 2007). On the other hand, Ahmed et al. (2009) found that, urea application in combination with humic acid and phosphate in soil can able to form $\mathrm{NH}_{4}^{+}$ more than $\mathrm{NH}_{3}$, and it can reduce environmental pollution. Therefore, soil application of the humic-acid increase soil water retention, and inhibit solubility of inorganic fertilizer. Also, the authors added that $\mathrm{NH}_{3}$ losses during 15 days of incubation are only $24,62 \%$ when compared to the losses of $\mathrm{NH}_{3}$ from urea about 48, and 80\%. Wang et al. (2001) showed that diffusion of humic-acid can enhance increase of $\mathrm{Ca}$ concentration and $\mathrm{pH}$ decrease thus increase the proton which makes humic-acid lack of negative charge and their intermolecular electric bondings are lower. Furthermore, humic-acid can be transformed from the large-molecule, flexible, and low ionic bond under alkaline condition, into the small molecule, rigid and high ionic bond under acidic condition. In improving efficiency of $\mathrm{N}$-fertilizer, ureahumate engineering is required, the urea-humate more stable and suggest a slow release of its nitrogen. Interaction of humic-acid with urea is not permanent; nitrogen can be released into the available forms. Interactions of humic-acid and urea can be analyses using FT-IR; it is expected that interaction between urea and humic-acid results in slower release of $\mathrm{N}-\mathrm{NH}_{4}^{+}$and $\mathrm{N}-\mathrm{NO}_{3}{ }^{-}$. This study is performed to examine interaction between urea and humic-acid at various concentrations in terms of N-NH${ }_{4}^{+}$and $\mathrm{N}-\mathrm{NO}_{3}{ }^{-}$release.

Also, Suntari et al. (2013) reported that urea-humate more stable and suggest a slow release of its nitrogen. Interaction of humic-acid with urea is not permanent; nitrogen can be released into the available forms. Coating urea with humic acids causes slow release of $\mathrm{N}\left(\mathrm{NH}_{4}^{+}\right.$and $\left.\mathrm{NO}_{3}{ }^{-}\right)$. The slow release of $\mathrm{N}\left(\mathrm{NH}_{4}^{+}\right.$and $\left.\mathrm{NO}_{3}^{-}\right)$of ureahumic acid in line with the rate of plant growth causes nitrogen losses reduced through volatilization and leaching. The available nitrogen can then be absorbed by plant roots as needed at each stage of growth. Thus, nitrogen loss can be prevented and, the efficiency of nitrogen application on growth can ultimately affect production of rice. Concerning the effect of polymerase, Rahman et al. (2008) reported that application of poly (acrylic urea) (PAU) and poly (meth acrylic urea) (PMAU), two different types of slow-release fertilizers and used for the covalent fixation of urea. This led 
to increase the $\mathrm{N}$ content in the fertilizer product. Also, Blaylock et al. (2005) found that a new slow-release urea product, polyurethane coated urea, has been commercially developed in which granular urea is coated with semipermeable layers of organic polymer resins. The polymer can be improves the yield and littered of the crops by improve the aero, thermo and water regime of the soil. Alkyd and carboxyl groups give the best characteristics possess of the polymer, Zlatković and Rašković (1998). In addition to, Drahn (2007) revealed that, Polymer-coated controlled release fertilizers (PCRF) offer several advantages to nurseries, especially those that grow small lots of many species or ecotypes such as easy to adjust fertilization type and rate for different crops. With the wide variety of N-P-K formulations and nutrient release timings, growers can easily customize their fertilization programs, better fertilizer use efficiency. Placing the fertilizer directly in the root zone is much more efficient than liquid fertilization that is lost when sprayed on benches or walkways, runs off the foliage, or drips through openings in containers. Along with, less fertilizer pollution in waste water, no rinsing required after fertilization. In additional, when rooting cuttings, incorporating PCRF into the rooting medium ensures that nutrients will be available as soon as roots form.

Urea-formaldehyde (UF) resins are poly condensation products of urea and formaldehyde in either alkaline or neutral or acid or alkaline/acid medium. Also, since the manufacturing costs of urea - formaldehyde resins are relatively the least expensive, and the raw materials are easily available, UF resin is perhaps the least expensive synthetic petrochemical adhesive (Edoga et al., 2001).Furthermore, Goertz (1993) reported that, sulfurcoated urea was one of the first coated controlled release fertilizers (CRF) and nitrogen release is controlled by the thickness of the sulfur coating.

Bentonite is clay consisting predominantly of smectite minerals, usually montmorillonite. Bentonite is used in a large array of applications (Virta, 2001). The use of cation beneficiated bentonite has been shown to increase soil exchange properties and plant growth on tropical Australian soils (Noble et al., 2001)However, the used of bentonitein can be contributed to excess of CEC in soil, when applied to low CEC soils, bentonite can bring about significant increases in the cation exchange capacity simply as a consequence of their high net permanent negative charge. As a factor of increasing soil CEC, bentonite can also improve the status of nutrients, enhancing agricultural productivity and improving fertilizer use efficiency(Croker et al., 2004).A further benefit of bentonite is that it has the capacity to increase plant available water as a function of increasing porosity (Soda et al., 2006).

The aim of this research is tested a new method of coated urea with different materials such as organic and inorganic (potassium humate and bentonite), synthetic conditioner polyacrylamide (PAM) to reduce nitrogen loss from leaching by irrigation or the volatilization. Also, can be use coated urea to improve crop especially under light texture (sandy soil) which reflected on the reduce of fertilizer consumption. Moreover, some chemical properties of sandy soils have been improved as a result of the use of soil conditioner bentonite, potassium humate and polyacrylamide for coated urea.

\section{MATERIALS AND METHODS}

To perform the objectives of this study, lab experiments were carried out at the lab of Soil Physics \& Chemistry Section Agric. Res. Center (ARC), Giza, Egypt followed by a field experiment at El-Ismailia Agric. Res. Station.

\section{Lab experiments.}

\section{1 -Preparing coated urea.}

The preferred urea granule $(46 \% \mathrm{~N})$ used for this purpose was approximately $5 \mathrm{~kg}$, where the work was done as follows:

1 - Method used for urea humate by spraying the urea fertilizer with the solution of potassium humate $(\mathrm{KH}) \mathrm{pH}$ 7.50 then left over night until the urea transfer to urea humate, this according to Suntari et al. (2013) (step a).

2- Add $100 \mathrm{~g}$ polyacrylamide (PAA) to different concentration of bentonite $(0.5,1,1.5,2$ and $2.5 \%)$ and mix well (step b).

3 - Add (b) to (a), provided that the urea is moistened with potassium humate. Then mix well and gently rub until the different concentrations of bentonite were bound with urea and to it by polyacrylamide and leave to dry in the laboratory atmosphere. Then the urea was coated with bentonite (CUB).

\section{2- Dissolution rate.}

$5 \mathrm{~g}$ from each type of (CUB) $(0.5,1,1.5,2$ and $2.5 \%$ of bentonite ) put in a beaker containing $50 \mathrm{ml}$ of distilled water maintained at room temperature. Magnetic stirrer was used at constant speed. The time required for complete dissolution of urea was noted down. (Vashishtha et al., 2010)

\section{3- Percent coating.}

$10 \mathrm{~g}$ from each type of (CUB) $(0.5,1,1.5,2$ and 2.5 $\%$ of bentonite ) were immersed in $100 \mathrm{ml}$ water. After vigorously shaking, the coating was liberated from the urea. Sub-squinty, the coating was obtained after filtration and evaporation of the water. Percent coating $=$ weight the filter coating (g) / weight of sample X100 (Salman, 1988).

\section{4- Investigation of the water absorption.}

The leachate water is collected from the previous experiment, which expresses the water absorbed by the urea covered and calculated as follows:

\section{V1 -V2$$
\text { V1 }
$$ \\ X 100}

V1 volume of water added to the sample, $V 2$ volume of the calculated from leachate These methods according to Vashishtha et al. (2010)

\section{5- Incubation experiment.}

The incubation experiment was designed to evaluate the effect of incubation period using urea coated with different percentage of bentonite $(0.5,1.0,1.5,2$ and $2.5 \%)$ against urea without coated to assess the effectiveness of CUB by the loss of nitrogen in the result of irrigation in pots which weight of one $\mathrm{kg}$ of sandy soil. The leachate was taken at period of $(5,10,15$ and 20 days, respectively) to determine the rate of nitrogen loss due to irrigation.

\section{6- Characterization of the double urea coating by} FTIR.

The outer coating martial of urea coated (bentonite and polyacrylamide) as well as the inner coating (potassium humate) were measured by a Fourier 
Transform Infrared (FTIR) spectrophotometer model Bruker Germany.

\section{Field experiment}

A trail experiment was laid out at Ismailia Agric. Res. Station, ARC during two successive winter seasons of 2015/ 2016 and 2016 /2017. Wheat crop (Triticum aestivum L,) was cultivated under sprinkler irrigation system to evaluate the urea humate coated by duple layers of poly phenyl acryl amide and bentonite as a slow release of nitrogen with using different rates of nitrogen $(100,75$ and $50 \% \mathrm{~N}$ of recommended doses), some soil chemical properties, also evaluated the wheat productivity and nutrients uptake. Institute farm is located at $30^{\circ} 35^{\prime} 41.9^{\prime \prime} \mathrm{N}$ Latitude and $32^{\circ} 16^{\prime} 45.8^{\prime \prime} \mathrm{E}$ longitude. Soil under study was analyzed according to methods described by Cottenie et al., (1982) was shown in Table (1). Chemical properties of bentonite and potassium humate are shown in Tables (2 and 3). The experiment was designed in a randomized complete block design with three field replications.

Table 1. Physical and chemical properties of the experimental soil

\begin{tabular}{|c|c|}
\hline parameters & Value \\
\hline \multicolumn{2}{|l|}{ Particle size distribution \% } \\
\hline Coarse Sand & 50.4 \\
\hline Fine Sand & 40.4 \\
\hline Silt & 3.20 \\
\hline Clay & 6.00 \\
\hline Texture class & Sandy \\
\hline \multicolumn{2}{|l|}{ Chemical properties } \\
\hline $\mathrm{CaCO}_{3} \%$ & 1.40 \\
\hline $\mathrm{pH}$ suspension $1: 2.5$ & 7.92 \\
\hline $\mathrm{EC}\left(\mathrm{dSm}^{-1}\right)$ saturated paste extract & 0.37 \\
\hline Organic matter \% & 0.40 \\
\hline \multicolumn{2}{|l|}{ Soluble cations and anions meq $\mathrm{L}^{-1}$} \\
\hline $\mathrm{Ca}^{++}$ & 0.95 \\
\hline $\mathrm{Mg}^{++}$ & 0.89 \\
\hline $\mathrm{Na}^{+}$ & 1.51 \\
\hline $\mathrm{K}^{+}$ & 0.45 \\
\hline $\mathrm{CO}_{3}^{--}$ & - \\
\hline $\mathrm{HCO}_{3^{-}}$ & 1.42 \\
\hline $\mathrm{Cl}-$ & 1.02 \\
\hline $\mathrm{SO}_{4}^{-}$ & 1.36 \\
\hline \multicolumn{2}{|l|}{ Available nutrients $\mathrm{mg} \mathrm{kg}^{-1}$} \\
\hline $\mathrm{N}$ & 66.0 \\
\hline $\mathrm{P}$ & 12.0 \\
\hline $\mathrm{K}$ & 45.6 \\
\hline
\end{tabular}

\section{Treatments}

1-Three rates of recommended dose from nitrogen (100, 75 and $50 \% \mathrm{~N}$ )

2- Three sources of nitrogen fertilizer (urea, coated urea and urea formaldehyde).

Apply phosphorus in the form of $\left(15 \% \mathrm{P}_{2} \mathrm{O}_{5}\right)$ at $200 \mathrm{Kg} \mathrm{fed} .^{-1}$ basically before sowing; potassium was apply in the form potassium sulfate $\left(48 \% \mathrm{~K}_{2} \mathrm{O}\right)$ at $50 \mathrm{Kg}$ fed. $^{-1}$ Nitrogen was apply at two doses except urea formaldehyde was applied before sowing. At harvest plants were taken to evaluate yield components (grains and straw) and nutrient status. Plant samples were oven dried at $70{ }^{\circ} \mathrm{C}$ until constant dry weight, then ground and digested using $\mathrm{H}_{2} \mathrm{SO}_{4}$ and $\mathrm{H}_{2} \mathrm{O}_{2}$ mixture described in Page et al. (1982). Surface soil samples were subjected to analyses some chemical parameters including $\mathrm{pH}$, organic matter and available $\mathrm{N}, \mathrm{P}$ and $\mathrm{K}$ along with analyses for natural minerals were evaluated according to procedures described by Cottenie et al. (1982).
Table 2. Selected chemical properties of potassium humate

\begin{tabular}{lclc}
\hline Parameters & Values & Parameters & Values \\
\hline $\mathrm{pH}$ & 7.50 & $\mathrm{P} \mathrm{mg} \mathrm{L}$ & 9.60 \\
$\mathrm{OC} \%$ & 0.63 & $\mathrm{Ca} \mathrm{mg} \mathrm{L}$ & 400 \\
$\mathrm{OM} \%$ & 1.08 & $\mathrm{Mg} \mathrm{mg} \mathrm{L}$ & 336 \\
$\mathrm{C} / \mathrm{N}$ & 1.21 & $\mathrm{Fe} \mathrm{mg} \mathrm{L}$ & 10.9 \\
$\mathrm{~N} \%$ & 0.52 & $\mathrm{Mn} \mathrm{mg} \mathrm{L}$ & 1.70 \\
$\mathrm{~K} \%$ & 4.00 & $\mathrm{Zn} \mathrm{mg} \mathrm{L}$ & 0.30 \\
$\mathrm{Na} \%$ & 0.83 & $\mathrm{Cu} \mathrm{mg} \mathrm{L}$ & 0.50 \\
\hline
\end{tabular}

Table 3. Selected chemical properties of the natural bentonite

\begin{tabular}{lccccccc}
\hline $\mathbf{p H}$ & $\begin{array}{c}\mathbf{E C} \\
\mathbf{d S m}^{-1}\end{array}$ & $\begin{array}{c}\mathbf{O C} \\
\mathbf{\%}\end{array}$ & $\begin{array}{c}\text { OM } \\
\mathbf{\%}\end{array}$ & $\begin{array}{c}\mathbf{C E C} \mathbf{c m o l} \\
\mathbf{k g}^{-1}\end{array}$ & $\begin{array}{c}\mathbf{N ~ m g} \\
\mathbf{k g}^{-1}\end{array}$ & $\begin{array}{c}\mathbf{P ~ m g} \\
\mathbf{k g}^{-1}\end{array}$ & $\begin{array}{c}\mathbf{K ~ m g}^{-1} \\
\mathbf{k g}^{-1}\end{array}$ \\
\hline 8.01 & 3.77 & 0.79 & 1.36 & 64 & 350 & 8.38 & 783 \\
\hline
\end{tabular}

Obtained results were subjected to statistical analysis according to Snedecor and Cochran (1982) and the treatments were compared by using the least significant difference (L.S.D) at 0.05 level of probability.

\section{RESULTS AND DISCUSSION}

\section{The structure and Photos of urea coated.}

Figs (1 and 2) show a detailed model of urea coated which design with potassium humate as inner layer and bentonite + polyacrylamide as the outer layer (fig. 1) along with a picture of it which appeared in yellow color, is the color of bentonite used. That means urea was coated by natural mineral clay, organic component and synthetic soil conditioner which retrain the urea to a good martial for fertilization.

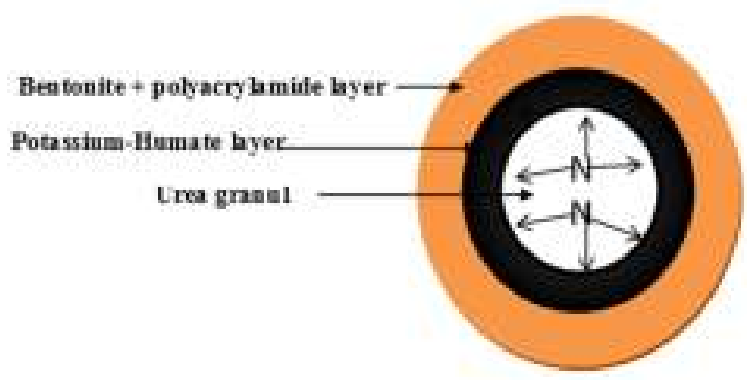

Fig 1. The cross section schematic of coated urea with double layers of potassium humate and bentonite + polyacrylamide
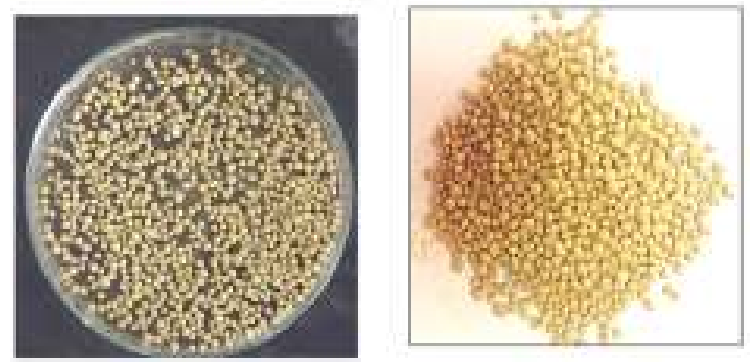

Fig 2. Photo of precuts coated urea

\section{Incubation experiment.}

The study of behavior of coated urea with different percentage of bentonite on release of nitrogen is shown in Fig (3). Obtained results revealed that differences in the behavior of the released nitrogen, which is the leachate in the given uncoated urea and coated urea with different concentration of bentonite. In the first five days, there was no variable difference between all treatments, while the 
amount of nitrogen released from urea at 10 and 15 days was greater than coated urea on the other word, the losses of $\mathrm{N}$ by leachate was more ever in uncoated urea, then decreased towards 20 days in all treatments. Obtained data indicated that the percentage of bentonite $2.5 \%$ seems to be favorable than other treatments thus, was taken in consideration when preparation in urea coated.

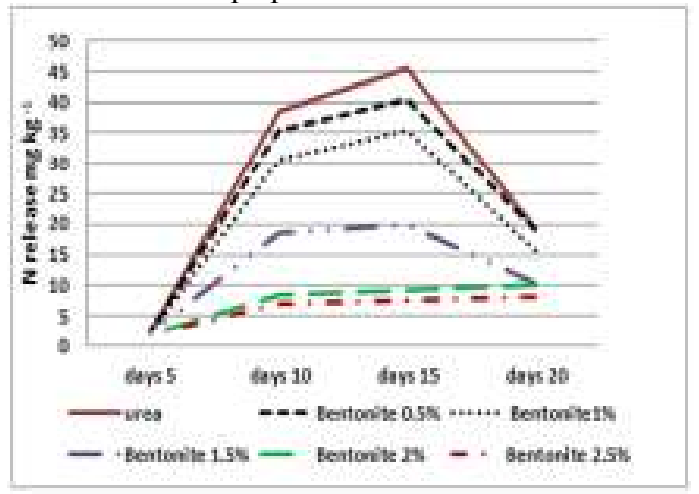

Fig 3. Effect of coated urea on release of nitrogen

From the above, the efficiency of coated urea on slow release of nitrogen was due to several reasons which will be clear as shown. The first reason, change in the chemical structure of the urea as a result of potassium humate which return urea to urea humate. Suntari et al. (2013) suggested that the potassium - humate contained the total acidity, carboxyl group and $\mathrm{OH}-$ phenol. This groups were interaction with urea to producing aromaticamide group $\left(\mathrm{R}-\mathrm{C}=\mathrm{O}-\mathrm{NH}_{2}\right)$. Also, Tan (1991) reported that urea humate complex reaction can occur through the two possible models which shown in Fig (4). Whereas, the negative charge on the carboxyl group can bind $\mathrm{NH}_{4}^{+}$, the urea-humate fertilizer showed a slower release of $\mathrm{NH} 4^{+}$. Interactions in urea-humate binding were involved covalen bonds and hydrogen-bonds. Covalen bond between aromatic group of carbonyl in humate and amide group in urea forming were more stable aromatic-amide compound. This bond makes urea humate more difficult to degrade. On the other hand, the existence of hydrogen-bonds in the dipolar water molecule can bind urea and potassium humate.

The second reason, the effect of polyacrylamide on urea use a glutinous adhesive to bind bentonite with urea granule to create a combination to coated urea. This polymer/clay nancomposites frequently exhibit excellent physical, mechanical and other properties, compared to those of pure superabsorbent or conventional superabsorbent composites, attributed to the nanoscale dispersion of clay in the polymer matrix, high aspect ratio of clay platelets and interfacial interaction between clay and polymers this according to (Liu et al., 2008). In addition to, the chemical component of polyacrylamide was - $\mathrm{CH} 2-\mathrm{CHCONH} 2-$ which described that the acrylic acid moieties present in the polymeric chain are more hydrophilic than that those of the other co-monomer. The ionization of acrylic acid as acrylate ions further increases its affinity for water absorption. (Shahid et al., 2012)
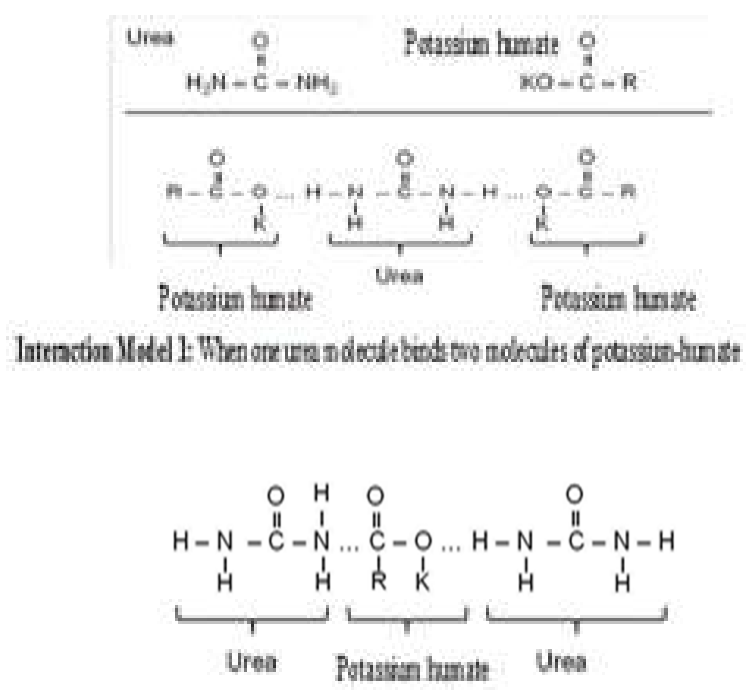

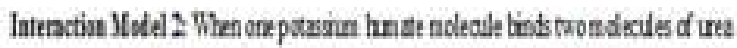

Fig 4. Two models of urea when correlated with potassium humate and transformed to urea humate

Other reason, the role of bentonate is also known to be of minerals type structure 2: 1 , whose physical properties are bloating when wet. In addition, it is a powder and has a very soft feel which makes it easier to wrap urea and acts like a rubber generation and when dry it is like a capsule on the urea granule. This crystalline structure (octal tetra hydra) can hold ammonium ion between the engineering structures of bentonite, making urea more stable and not lose either by leaching or volatilization. This agree with resultant of Abou El magd and Taha (2012) who found the role of bentonite as filler involves adsorption of ammonium nitrate (AM) component on its outer surface due to probable fixation of AM by isomorphous replacement in the crystal lattice of bentonite. Beside, bentonite retains some of ammonia through adsorption on its outer surface leaving the chance for its gradual absorption by plants.

\section{2- Dissolution rate.}

Fig (5) described the influence of bentonite percentage and polyacrylamide on dissolution rate. The solution of urea decreased when bentonite percentage was increased which expressed the rate of time. This due to the bentonite and polymer working as physical barrier to urea release, so the increase of bintonite coating lead to decreases the rate of dissolution. The results are consistent with Vashishtha et al. (2010). The same phenomenon is also found in studies conducted by Choi and Meisen (1997) regarding the use of sulfur coating urea, and Ozturkon the coating of urea using Ethyl cellulose .also, the same resultant agree with Suherman and Anggoro (2011) who found the favorable dissolution rate with increase percentage coating materials of urea regardless the kind of material was used.

\section{3- Percent of coating.}

Fig (6) showed that the higher concentration of bentonite in urea coating given the grater percent of coating. Solution concentration is a parameter which has affect to the duration of the operation and growth mechanisms. When the operation takes place at high concentrations, the degree of 
saturation during drying can reach a maximum. This leads to an increase in the rate of crystallization on the surface of the particles. The greater concentration reflect that the content of bentonite in the composite (polyacrylamide and potassium humate) more and more, so the possibility of attachment of bentonite on the surface of the particle the greater urea. This agree with resultant of Salman et al. (2007); Suherman and Anggoto (2011) who using the starch coating for urea.

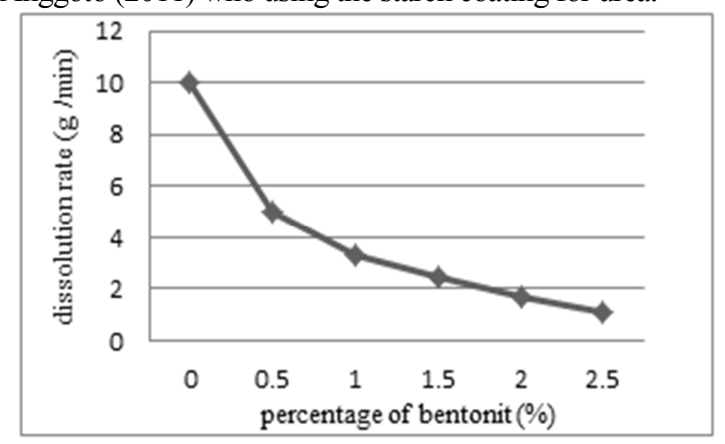

Fig 5. The influence of bentonite weight in coating solution on dissolution rate urea

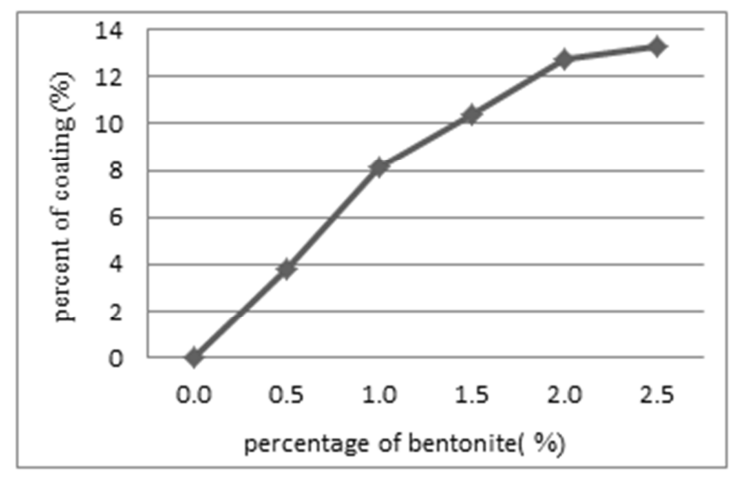

Fig 6. The influence of bentonite weight on percent of coating urea

\section{4- Behavior of water absorption.}

The results in Fig (7) revealed that the percent of absorption water within different concentration of bentonite along with bolyacrylamide which coating urea fertilizer. The greater absorbency of water were shown at 2 and $2.5 \%$ bentonite this similar resultant by Elly et al. (2006) who explained minerals clay type 2:1 are a complex structure which is crystalline inorganic polymers based on an expanded tetrahedral framework infinite from $\mathrm{AlO} 4$ and $\mathrm{SiO} 4$ and connected to each other through joint distribution of oxygen ions. This framework structure contains channels filled by cations and water molecules. In addition to, the ability of potassium humate whish involved in urea coated to absorb water because it contain many carboxylic functional group (- COOH). According to Tan (1996) carboxylic have strong attraction to water molecules and water can be bound through a single bond or hydrogen multi bonds.

In the other word, the water was retention in this combination and stored between the structures. Also, $\mathrm{Wu}$ and Liu (2008) found that the hydrophilic group plays an extremely important part in water absorbency which found in polyacrylamide (PAA).So that the hydroxyl groups on the surface of bentonite would react with the carboxyl group of (PAA). The subsequent water absorbency increase may be due to the effect of electro static interactions on the polymer chains. (Santiago et al., 2007)

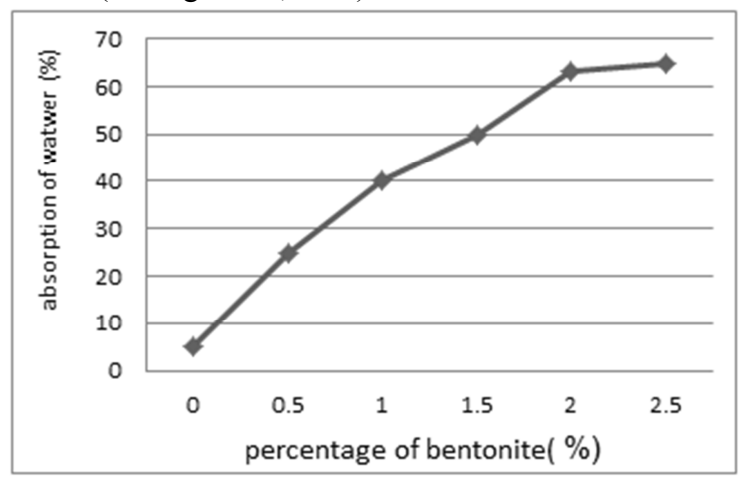

Fig 7. The influence of bentonite weight on water absorption by coating urea

\section{5- Composition of functional groups of urea coated by} FTIR.

To complete the picture, Fig (8) and Table (4) showed the FTIR spectra of urea coated as collocation of materials used in coating (betonite, potassium humate and polyacrylamidein addition to urea). The existence of vibration absorption corresponding of $3429.18 \mathrm{~cm}^{-1}$ to 2813 $\mathrm{cm}^{-1}\{\mathrm{O}-\mathrm{H}$ or $\mathrm{N}-\mathrm{H}\}$ suggested that potassium humate and urea. Which bind to $\mathrm{KH}$ then transfer to urea humate was continued $\mathrm{O}-\mathrm{H}$ chain with intermolecular $\mathrm{H}$-bond in form of polymers (Tan 1996). Also, MC Murry (1999) observed that, the aromatic- amide group $\left(\mathrm{R}-\mathrm{C}=\mathrm{O}-\mathrm{NH}_{2}\right)$ corresponding $1675 \mathrm{Cm}^{-1}$ with FT-IR producing from potassium humate and urea. Corresponding the $\mathrm{C} \square \mathrm{C}$, $\mathrm{C} \square \mathrm{N}, \mathrm{C}=\mathrm{O}, \mathrm{C}=\mathrm{N}, \mathrm{C}-\mathrm{H}$ and $\mathrm{C}-\mathrm{N}$ at wave numbers 2468.21 to 1456.55 . The same groups function of bentonite were suggested with esultant by (Qin et al., 2012) these results obvious the outer and inner coating which incorporation with urea to convert to urea coated.

Table 4. Wave numbers and functional groups of coated with potassium humate, bentonite and poilyacrylamide

\begin{tabular}{|c|c|c|}
\hline$\overline{\text { No }}$ & Functional groups & Wave numbers $\left(\mathrm{cm}^{-1}\right)$ \\
\hline$\overline{1}$ & $\mathrm{X}-\mathrm{O}-\mathrm{H} \quad \mathrm{X}=\mathrm{Al}, \mathrm{Mg}$ & 3620.69 \\
\hline 2 & $\mathrm{H}-\mathrm{O}-\mathrm{H}$ and $\mathrm{N}-\mathrm{H}$ & 3429.18 \\
\hline 3 & $\mathrm{NH} 2$ & 3332.61 \\
\hline 4 & $\mathrm{O}-\mathrm{H}$ and $\mathrm{N}-\mathrm{H}$ & 3255.39 \\
\hline 5 & $\mathrm{C}-\mathrm{H}$ & 2924.66 \\
\hline 6 & $\mathrm{O}-\mathrm{H}, \mathrm{N}-\mathrm{H}, \mathrm{C}-\mathrm{H}$ & 2813.00 \\
\hline 7 & $\mathrm{C}=\mathrm{C}$ & 2468.21 \\
\hline 8 & $\mathrm{C}=\mathrm{C}$ & 2319.28 \\
\hline 9 & $\mathrm{C}=\mathrm{C}$ & 2112.08 \\
\hline 10 & $\mathrm{C}=\mathrm{O}$ & 1675.04 \\
\hline 11 & $\mathrm{C}=\mathrm{C}, \mathrm{C}=\mathrm{O}, \mathrm{C}=\mathrm{N}$ & 1591.31 \\
\hline 12 & $\mathrm{C}-\mathrm{OH}, \mathrm{C}-\mathrm{N}$ & 1456.55 \\
\hline 13 & $\mathrm{Si}-\mathrm{O}$ & 1146.70 \\
\hline 14 & $\mathrm{Si}-\mathrm{O}-\mathrm{Si}$ & 1004.77 \\
\hline 15 & $\mathrm{Sio} 2$ & 784.52 \\
\hline 16 & Si-O, AL-O & 709.91 \\
\hline 17 & Si-O-AL & 544.56 \\
\hline 18 & $\mathrm{Si}-\mathrm{O}-\mathrm{Si}$ & 458.32 \\
\hline
\end{tabular}




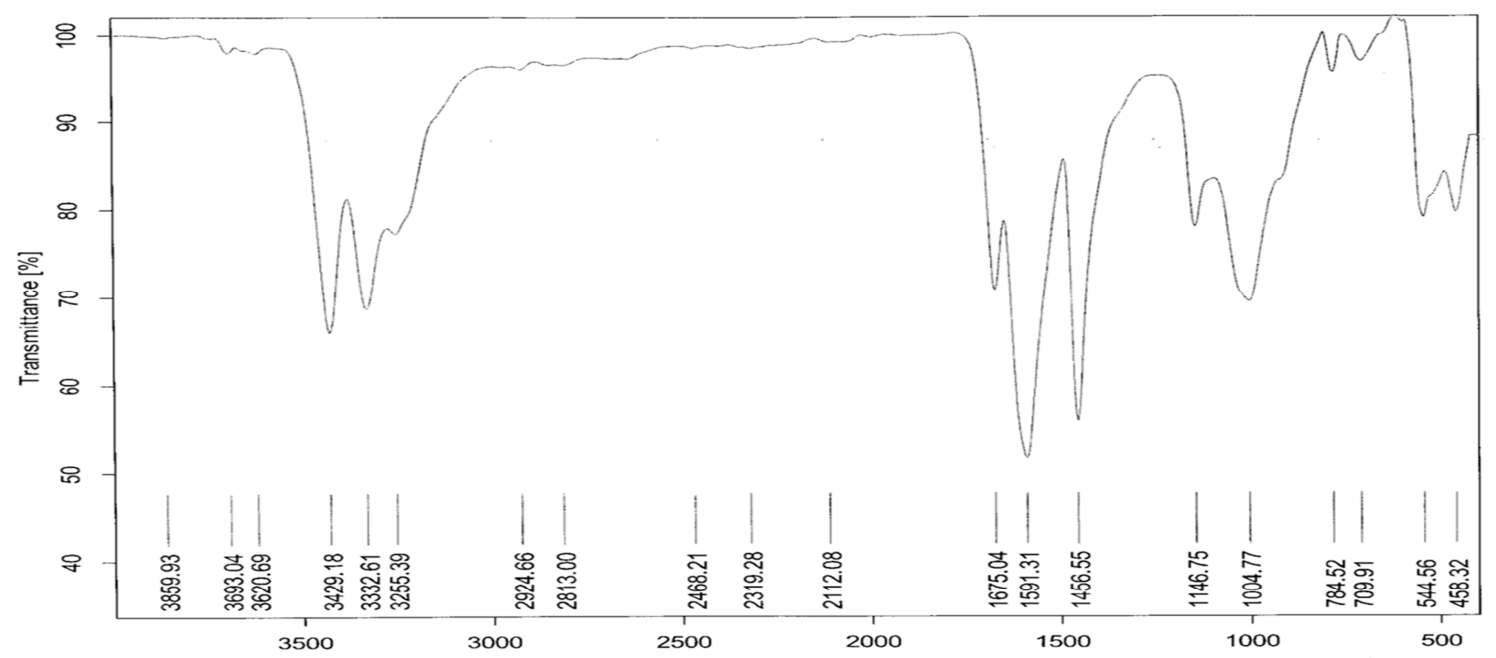

Fig 8. FTIR spectra of urea coated with potassium humate ,bentonite poilyacrylamide

\section{6 - Field experiment.}

From the above mention, use the quantity of bentonite for coated urea along with polyacrylamide and potassium humate which apply to the soil with three rates of nitrogen 100, 75 and $50 \% \mathrm{~N}$ from the recommended dose. Also, urea formaldehyde and uncoated urea were used for a comparatives and the extent of urea coating on the chemical properties of sand soil such as $\mathrm{pH}, \mathrm{EC}$ and available macronutrients shown in Table (5)

\section{Soil pH.}

Generally, the mean values of soil $\mathrm{pH}$ in two studied seasons were decreased with urea form and coated urea compared to uncoated urea (control). With consideration, reduce of $\mathrm{pH}$ values were significant affected by urea coated (bentonite and polyacrylamide along with potassium humate). This may be due to nature of coated materials which change in combination of urea and retrain to urea humate which makes lack of negative charge and increase of proton whereas the intermolecular electric bondings are lower (Wang et al., 2001). In addition to found the carboxyl group in this stricture can reduce the $\mathrm{pH}$ soil; this results are agreement with those obtained by (MC Murry, 1999; Suntari et al., 2013). Along with, used bentonte as coated of outer surface urea granule can decrease the $\mathrm{pH}$ values in soil by release the $\mathrm{H}^{+}$ions to the soil solution due to the exchangeable ions which adsorbed the some ions from soil (Abou El magd and Taha, 2012).

Meanwhile, the effect of nitrogen concentrations rates was shown no significant responses between different rates. The interactions effect between nitrogen rates and treatments (urea formaldehyde or urea coated) showed no obvious differences in the $\mathrm{pH}$ (Bai et al., 2010). On the other hand, the effect of urea coated show slightly degree decrease between rates of nitrogen.

Table 5. Effect of coated urea on some soil chemical parameters with different rates of nitrogen at two seasons

\begin{tabular}{|c|c|c|c|c|c|c|c|c|c|c|c|}
\hline \multirow{3}{*}{ Treat. } & & \multicolumn{6}{|c|}{ First season } & \multicolumn{4}{|c|}{ Second season } \\
\hline & & \multirow[t]{2}{*}{ pH } & \multirow[t]{2}{*}{$\mathrm{EC} \mathrm{dSm}{ }^{-1}$} & \multicolumn{3}{|c|}{$\begin{array}{c}\text { Available } \\
\text { macronutrients }\left(\mathrm{mg} \mathrm{kg}^{-1}\right)\end{array}$} & \multirow[t]{2}{*}{ pH } & \multirow[t]{2}{*}{$E C \mathrm{dSm}^{-1}$} & \multicolumn{2}{|c|}{$\begin{array}{c}\text { Available } \\
\text { macronutrients (mg }\end{array}$} & \multirow{2}{*}{$\begin{array}{l}\left.\mathbf{k g}^{-1}\right) \\
\mathrm{K}\end{array}$} \\
\hline & & & & $\mathbf{N}$ & $\mathbf{P}$ & K & & & $\mathbf{N}$ & $\mathbf{P}$ & \\
\hline & 100 & 8.00 & 0.54 & 200 & 32 & 55 & 7.99 & 0.59 & 224 & 31 & 39 \\
\hline \multirow[t]{2}{*}{ Urea } & 75 & 8.19 & 0.43 & 196 & 18 & 36 & 7.93 & 0.45 & 205 & 29 & 36 \\
\hline & 50 & 8.19 & 0.35 & 168 & 15 & 29 & 7.81 & 0.37 & 189 & 27 & 35 \\
\hline \multirow[t]{2}{*}{ Mean } & & 8.13 & 0.44 & 188 & 22 & 40 & 7.91 & 0.47 & 206 & 29 & 37 \\
\hline & 100 & 8.10 & 0.56 & 210 & 67 & 49 & 7.61 & 0.67 & 227 & 40 & 45 \\
\hline \multirow{2}{*}{ Urea form } & 75 & 8.06 & 0.55 & 191 & 26 & 41 & 7.94 & 0.59 & 217 & 31 & 40 \\
\hline & 50 & 8.02 & 0.44 & 186 & 16 & 32 & 7.96 & 0.47 & 187 & 29 & 36 \\
\hline \multirow[t]{2}{*}{ Mean } & & 8.06 & 0.52 & 196 & 36 & 41 & 7.84 & 0.58 & 210 & 33 & 40 \\
\hline & 100 & 8.04 & 0.88 & 233 & 61 & 62 & 7.61 & 0.88 & 249 & 40 & 58 \\
\hline \multirow[t]{2}{*}{ Coated urea } & 75 & 7.89 & 0.65 & 210 & 51 & 54 & 7.42 & 0.59 & 243 & 39 & 49 \\
\hline & 50 & 7.78 & 0.55 & 200 & 26 & 53 & 7.25 & 0.63 & 226 & 25 & 41 \\
\hline Mean & & 7.09 & 0.69 & 214 & 46 & 56 & 7.43 & 0.70 & 239 & 35 & 49 \\
\hline \multicolumn{12}{|c|}{ Mean of N concentration } \\
\hline $100 \% \mathrm{~N}$ & & 8.08 & 0.67 & 214 & 53 & 55 & 7.73 & 0.71 & 233 & 37 & 47 \\
\hline $75 \% \mathrm{~N}$ & & 8.07 & 0.54 & 199 & 31 & 44 & 7.76 & 0.54 & 222 & 33 & 43 \\
\hline $50 \% \mathrm{~N}$ & & 8.03 & 0.44 & 184 & 19 & 41 & 7.67 & 0.44 & 207 & 27 & 38 \\
\hline \multicolumn{12}{|l|}{ L.S.D } \\
\hline $\mathrm{A}($ Treatments) & & 0.215 & 53.7 & 53.7 & 2.01 & 7.09 & 0.10 & 0.41 & 20.1 & 9.26 & 8.99 \\
\hline $\mathrm{B}($ Concentration) & & 0.951 & 1.56 & 1.56 & 1.23 & 2.18 & 0.86 & 0.41 & 1.50 & 3.37 & 3.08 \\
\hline$A * B$ & & 0.689 & 50.9 & 50.9 & 15.8 & 12.5 & 0.91 & 0.56 & 45.3 & 1.40 & 16.6 \\
\hline
\end{tabular}




\section{Electrical conductivity (EC).}

Results in Table (5) revealed that, mean values of EC in soil were increased with urea coated compare to other treatments this opposite trend was observed with respect to changes in $\mathrm{pH}$ values. Obtained results coincided well with findings of Bai et al. (2010), who found the exchangeable ions in polymers with coated urea can influence in nutrients availability which increase the EC. As a resultant expected, the increased of rates nitrogen fertilizer EC values were increasing during both tested seasons beside interactions effect.

\section{Nutrients availability (N, P and $K)$}

Data representing availability of soil nutrients $\mathrm{N}, \mathrm{P}$ and $\mathrm{K}$ in two seasons are shown in Table (5). Concerning nitrogen, the mean values of $\mathrm{N}$ availability under effect of urea coated and urea formaldehyde were increased significantly compared to uncoated urea. With considerable the superior treatments were observed when apply the urea coated. This may be due to the same obvious mention reasons like the transfer urea to urea humate which improve the availability of $\mathrm{N}\left(\mathrm{N}_{-} \mathrm{NO}_{3}\right.$ and $\left.\mathrm{NH}_{4}\right)$ (Suntari et al., 2015). Furthermore, the composition of urea coated (bentonite and polyacrylamide) can be attributed to retrain the water and elements which keep them between the structure which improve the status availability of nutrients (Shahid et al., 2012). Moreover, Bai et al. (2010) suggested that the sharp decrease in $\mathrm{pH}$ can be release the elements in soil solution. Along with particle size and gel strength from polymer was the largest in urea coated. This means that nitrogen in soil had been a good product from washing and released slow from urea coated ( $\mathrm{Wu}$ and $\mathrm{Liu}, 2008$ ). With expected to the available nitrogen was increase with increased the rates of nitrogen along with the interaction effect between treatments. The same results were observed with the availability of phosphorus and potassium. These really, because the bentonite which coated outer the granular urea can be increase adsorption the minerals nutrients on cation exchange sites which increase the nutrients availability in soil solution (Huett and Gogel, 2000).

\section{Plant behavior}

\section{Plant growth}

Data in Table (6) and Fig (9) show that the effect of urea coated on productivity of straw, grain and biological yield of wheat crop with compared to uncoated urea and urea- formaldehyde.

As expected from the previous discussion, the mean values of the biological yield, grains and straw of the ureacoated and urea formaldehyde were increases compared to urea uncoated. But it was observed that this increase was better when applying urea coated for the same reasons mentioned above which corresponds to the nature of the covered material. Which has obtained urea fertilizer good qualities could be affecting the physical and chemical soil properties. For example, the presence of polycrylamide increases the soil saturation and retention of water, giving a good chance of good germination of the wheat grain and thus higher yield than others. The same results were agree with resultant by Shahid et al. (2012) who found that the polymer and hydrogel can enhancement the soil moisture and retention which improve the seed germination and seedling growth. Bentonite also works to retain nitrogen and not to lose it by leaching or evaporation. In addition to, being bind to other elements, giving the large opportunity to absorb the amount of necessary elements by plant which help in the growth and increase the crop productivity. As well as, the presence of potassium humate which convert urea to urea humate. It has a role in the chelating of the elements in the soil writhen the function groups and supply to the plant, thus reflected on the increase of both grain and straw and total yield. There is also no significant increase between nitrogen levels and interference between treatments, which proves the maximum benefit of nitrogen fertilization, which saved fertilization rates. This may be due to the effect of slow release of nitrogen as need to wheat plant requirement, where slow release has allow dissolution rate than urea (Taha et al., 2016); Shivay et al. ( 2016) also confirmed this discussion who reported that slow release of $\mathrm{N}$ caused a larger crop of grain and straw.

Table 6. Effect of urea coated on straw and grains of wheat crop with different rates of nitrogen at first and second seasons

\begin{tabular}{lccccc}
\hline \multirow{2}{*}{ Treat. } & & \multicolumn{4}{c}{ Ton fed $^{-1}$} \\
\cline { 3 - 6 } & & \multicolumn{2}{c}{ First season } & \multicolumn{2}{c}{ Second season } \\
\cline { 3 - 6 } & 100 & 2.00 & 1.41 & 3.14 & 2.54 \\
Urea & 75 & 1.92 & 1.23 & 2.78 & 2.29 \\
& 50 & 1.49 & 0.97 & 2.19 & 1.46 \\
Mean & & 1.80 & 1.21 & 2.70 & 2.10 \\
\hline \multirow{3}{*}{ Urea form } & 100 & 2.19 & 1.85 & 3.39 & 2.86 \\
& 75 & 2.03 & 1.84 & 3.00 & 2.48 \\
Mean & 50 & 1.80 & 1.75 & 2.74 & 2.23 \\
& & 2.01 & 1.81 & 3.04 & 2.52 \\
Coated urea & 100 & 3.19 & 2.28 & 4.39 & 3.01 \\
& 75 & 2.64 & 1.98 & 3.36 & 2.84 \\
Mean & 50 & 1.88 & 1.89 & 3.14 & 2.55 \\
\hline Mean of N concentration & & & & \\
\hline 100\% N & & 2.57 & 2.05 & 3.63 & 2.80 \\
75\% N & 2.13 & 1.85 & 3.64 & 2.80 \\
50\% N & & 1.63 & 3.00 & 2.54 \\
\hline LSD & & & & & \\
A (Treatments) & & 0.603 & 0.232 & 0.323 & 0.692 \\
B(Concentration) & 0.209 & 0.162 & 0.160 & 0.294 \\
A*B & 0.622 & 0.332 & 0.113 & 0.743 \\
\hline
\end{tabular}

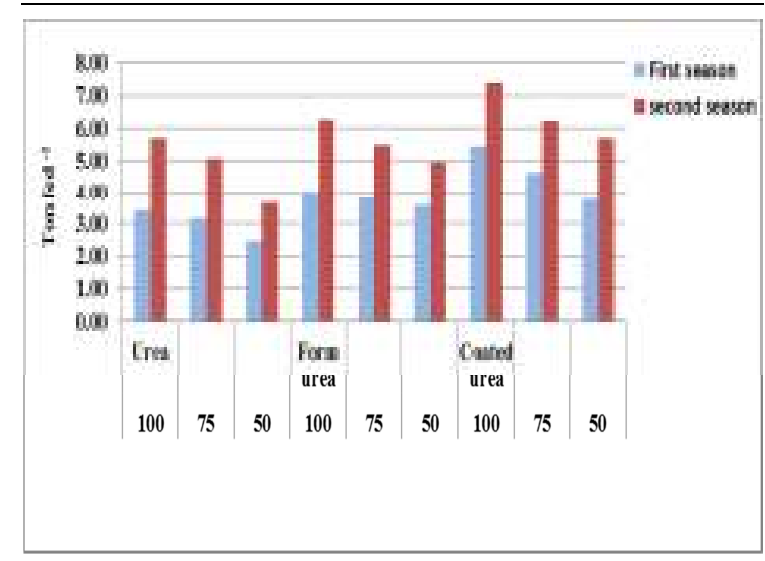

Fig 9. Effect of urea coated on biological yield of wheat crop in first and second seasons

2. Total content ( $N, P$ and $K)$.

Data in Table (7) showed the effect of urea coated on total content of macronutrients of nitrogen, phosphorus and potassium of wheat crop at first and second growth seasons. 
The same trend is expected to discuss the total content of the elements with a discussion of wheat growth. The total content of the elements increased under the influence of urea formaldehyde and urea coated compared to the uncoated urea. Generally, the results showed that the superior treatment was urea coated. As mentioned previously, the natural of coated material that led to the establishment of a good basis for growth, which helps in obtaining nutrients, and thus increase production capacity in terms of plant growth and increase the content of the total elements absorbed. Concerning the effect of nitrogen rates, data revealed an increase in the total content of the elements $\mathrm{N}, \mathrm{P}$ and $\mathrm{K}$, as well as the interaction effects

Table 7. Effect of urea coated on total content of $N, P$ and $K$ in straw and grain of wheat crop with different rates of nitrogen at first and second seasons

\begin{tabular}{|c|c|c|c|c|c|c|c|c|c|c|c|c|c|}
\hline \multicolumn{14}{|c|}{ Total content $\left(\mathrm{kg}\right.$ fed..$\left.^{-1}\right)$} \\
\hline \multirow{3}{*}{ Treat. } & & \multicolumn{6}{|c|}{ First season } & \multicolumn{6}{|c|}{ Second season } \\
\hline & & \multicolumn{3}{|c|}{ Straw } & \multicolumn{3}{|c|}{ Grains } & \multicolumn{3}{|c|}{ Straw } & \multicolumn{3}{|c|}{ Grains } \\
\hline & & $\mathbf{N}$ & $\mathbf{P}$ & $\mathbf{K}$ & $\mathbf{N}$ & $\mathbf{P}$ & $\mathbf{K}$ & $\mathbf{N}$ & $\mathbf{P}$ & $\mathbf{K}$ & $\mathbf{N}$ & $\mathbf{P}$ & $\mathbf{K}$ \\
\hline \multirow{3}{*}{ Urea } & 100 & 10.7 & 3.38 & 6.25 & 15.1 & 4.78 & 2.28 & 14.6 & 2.31 & 12.8 & 24.87 & 7.00 & 5.85 \\
\hline & 75 & 10.1 & 2.75 & 4.78 & 14.1 & 4.11 & 1.86 & 13.1 & 2.04 & 11.3 & 22.0 & 5.77 & 5.81 \\
\hline & 50 & 8.50 & 1.87 & 4.05 & 11.5 & 6.39 & 1.71 & 10.4 & 2.23 & 11.1 & 16.47 & 4.44 & 3.83 \\
\hline \multirow[t]{2}{*}{ Mean } & & 9.78 & 2.66 & 5.03 & 13.7 & 5.09 & 1.95 & 12.7 & 2.19 & 11.7 & 21.07 & 5.75 & 5.17 \\
\hline & 100 & 16.4 & 4.76 & 12.8 & 25.8 & 9.63 & 4.26 & 17.1 & 6.19 & 15.1 & 42.8 & 9.07 & 8.73 \\
\hline \multirow{2}{*}{ Urea form } & 75 & 13.6 & 4.99 & 7.11 & 24.9 & 8.66 & 4.44 & 14.7 & 5.77 & 15.3 & 27.4 & 6.93 & 7.41 \\
\hline & 50 & 8.96 & 6.37 & 9.57 & 25.1 & 7.12 & 3.47 & 13.8 & 3.51 & 12.5 & 22.93 & 6.5 & 5.47 \\
\hline \multirow[t]{2}{*}{ Mean } & & 12.9 & 5.37 & 9.83 & 25.3 & 8.47 & 4.06 & 15.2 & 5.16 & 14.3 & 31.07 & 7.47 & 7.2 \\
\hline & 100 & 14.0 & 5.19 & 7.00 & 22.1 & 6.49 & 3.48 & 21.9 & 4.53 & 17.8 & 34.27 & 8.33 & 8.07 \\
\hline \multirow[t]{2}{*}{ Coated urea } & 75 & 11.5 & 4.81 & 6.20 & 21.2 & 6.69 & 3.15 & 13.6 & 3.04 & 10.5 & 31.67 & 6.93 & 6.87 \\
\hline & 50 & 9.68 & 2.71 & 5.61 & 18.5 & 5.01 & 2.96 & 10.1 & 3.90 & 10.5 & 21.13 & 6.31 & 5.09 \\
\hline Mean & & 11.7 & 4.24 & 6.27 & 20.6 & 6.06 & 3.2 & 16.6 & 3.83 & 12.9 & 29.0 & 7.07 & 6.7 \\
\hline \multicolumn{14}{|c|}{ Mean of N concentration } \\
\hline $100 \% \mathrm{~N}$ & & 13.7 & 4.98 & 8.68 & 21.1 & 7.54 & 3.4 & 17.8 & 4.34 & 15.3 & 33.93 & 8.13 & 7.53 \\
\hline $75 \% \mathrm{~N}$ & & 11.7 & 4.18 & 6.85 & 20.1 & 6.64 & 3.09 & 13.8 & 2.29 & 12.3 & 26.87 & 6.53 & 6.71 \\
\hline $50 \% \mathrm{~N}$ & & 9.04 & 3.11 & 5.59 & 18.2 & 5.14 & 2.71 & 11.4 & 3.23 & 11.3 & 20.2 & 5.75 & 4.79 \\
\hline \multicolumn{14}{|l|}{$\overline{\mathrm{LSD}}$} \\
\hline A (Treatments) & & 6.25 & 3.64 & 2.35 & 5.69 & 3.84 & 1.58 & 1.77 & 4.02 & 7.18 & 9.533 & 4.28 & 2.98 \\
\hline $\mathrm{B}$ (Concentration) & & 2.01 & 1.29 & 1.67 & 1.09 & 1.61 & 1.17 & 2.01 & 1.02 & 1.21 & 2.707 & 1.74 & 2.413 \\
\hline $\mathrm{A}^{*} \mathrm{~B}$ & & 4.93 & 2.47 & 5.11 & 6.43 & 3.24 & 1.42 & 8.00 & 4.28 & 10.3 & 8.867 & 2.373 & 1.633 \\
\hline
\end{tabular}

\section{CONCLUSION}

Based upon the present study data, it could be concluded that controlled release urea has been successfully by coating with bentonite, polyacrylamide and potassium humate. The suitable quality for coating of bentonite and polyacrylamide were $2.5 \%$ and $0.1 \%$ respectively, which conformed by some experiments such as percent coating and dissolution rate. Along with investigation of the water absorption which showed the greater absorbency of water in $2.5 \%$ bentonite for coating. Analysis with FTIR spectra of urea coated were showed the function groups in outer (bentonite and polyacrylamide) and inner (potassium humate) coated which obtain the urea a new good nature. This reflected on some soil chemical properties whereas, the applied of coated urea after used this materials can be improve it such as $\mathrm{pH}, \mathrm{EC}$ and availability of $\mathrm{N}, \mathrm{P}$ and $\mathrm{K}$. In addition to save of consumption of nitrogen fertilizer by slow release of $\mathrm{N}$. Coated urea may be retention the water which beneficial in sandy soil. Finally, the status of wheat crop such as total yield, grain and straw were greater increase when addition of urea coated compared to other treatments as well as improvement the total content of macronutrients.

\section{REFERENCES}

Abou Elmagd, K. and G. M. Taha (2012). Novel procedure for minimizing the emission of nitrogen dioxide in manufacturing of azote fertilizer using aswan bentonite as filler. Inter.J. Basic \& Appl. Sci., 12: 102-107.

Ahmed, O.H., H. Ammuddin, M. Hanif, A. Husni, B. Jalloh, M.M.Mohamad, and N.A. Majid (2009). Enhancing the urea-N use efficiency in maize cultivation on acid soils using urea amended with zeolite and TSP. Am. J. App.Sci., 5: 829-833.
Bai, W., H. Zhang, B. Liu, Y. Wu and J. Song (2010).Effects of super absorbent polymers on the physical and chemical properties of soil following different wetting and drying cycles. Soil Use and Management, 26: 253-260.

Blaylock, A. D., J. Kaufmann and R. D. Dowbenko ( 2005). Nitrogen fertilizers technologies. Western Nutrient Management Conference. 6:8-13.

Choi, M.M. S. and A. Meisen (1997). Sulfur coating of urea in shallow pouted beds. Chem. Eng. Sci., 52: 1073-1086.

Cottenie, A., M. Verloo, L. Kiek, G. Velghe and R. Camerlynek (1982) "Chemical analysis of plants and soils" Lab. Anal. And Agroch. State Univ., Ghent, Belgium.

Croker, J., R. Poss, C. Hartmann and S. Bhuthorndharaj (2004). Effects of recycled bentonite addition on soil properties, plant growth and nutrient uptake in a tropical sandy soil. Plant \& Soil, 267: 155-163.

Drahn, S.R. (2007) .Propagating with controlled release fertilizer. Salem, OR. URL: http://www.ippswr.org.

Edoga, M. O., R. O. Ebewele and R. N. Anosike (2001). Comparison of modifiers for stability - durability improvement. Stability improvement of urea formaldehyde adhesives for wood products, Inter. J. Asso., 62: 45-60.

Elly, M.U., F.A. Yasnur and I.stadi. (2006). Optimasi pembuatan katalis zeolit $\mathrm{X}$ dari tawas, $\mathrm{NaOH}$ dan water glass dengan response surface methodology. Bull Chem. Reac. Engine. Catal, 3: 26-32.

Goertz, H. M. (1993). Controlled release technology. In KirkOthmer Encyclopedia of Chemical Technology, Fourth Edition, 7: 251-274.

Huett, D. O. and B. J. Gogel (2000). Longevities and nitrogen, phosphorus and potassium release patterns of polymercoated controlled-release fertilizers at $30^{\circ} \mathrm{C}$ and $40^{\circ} \mathrm{C}$. Common. Soil Sci. Plant Anal., 31:959-973.

Liu, Y. H., T. J. Wang, L. Qin and Y. Jin (2008). Urea particle coating for controlled release by using DCPD modified sulfur. Powder Techn., 183 : 88-93. 
Mc Murry, J. (1999). "Organic Chemistry" Fifth Edition. Brooks/ Cole, Cornell University. USA.

Noble, A. D., S. Nath and R. J. Srivastave (2001). Changes in the surface charge characteristics of degraded soils in the wet tropics through the addition of beneficiated bentonite. Aust. J. Soil Res., 39: 991-1001.

Nuryani, S.H.U., B. H. Purwanto, A. Maas, E.W.Wiwik, O. A. Bannati and K. D. Sasmita (2007). Peningkatan efisiensi pemupukan $\mathrm{n}$ pada tanaman tebu melalui rekayasa khelat urea-humat. J. Ilmu Tanah dan Lingkungan .7: 93-102.

Page,A.L., R.H. Miller and D.R. Keeney (1982)."Methods of soil analysis" Amer. Soc. Agron.,Madison, Wisconsin, U.S.A.

Qin, S., Z. Wu, A. Rasool, C. Li (2012). Synthesis and characterization of slow-release nitrogen fertilizer with water absorbency: based on poly(acrylic acid-acrylic amide)/Na bentonite. J. Appl. Poly. Sci., 126: 16871697.

Rahman, M. H., B. K. Das, M. A. J. Miah and H. Ahmad (2008). Fixation of urea to polyacrylic acid and nitrogen release behavior of the product (poly urea) - a comparison with urea and control (without nitrogen fertilizer). Asian J. Crop Sci., 1: 6-14.

Salman, O.A. (1988) "Polymer Coating on Urea Prills to Reduce Dissolution Rate", J. Agric. Food Chem., 36:616-621.

Salman, A.D., M.J. Hounslow and J.P.K. Seville (2007). Handbook of Powder Technology Granulation. Elsevier, UK

Santiago, F., A.E. Mucientes, M. Osorio and C. Rivera (2007). Preparation of composites and nanocomposites based on bentonite and poly (sodium acrylate).Effect of amount of bentonite on the swelling behavior. J. Europ. Poly.,43: 1-9.

Shahid, S.A., A. A. Qidwai, F. Anwar, I. Ullah, and U. Rashid (2012). Improvement in the water retention characteristics of sandy loam soil using a newly synthesized poly (acrylamide - co - acrylic acid) / $\mathrm{AlZnFe} 2 \mathrm{O} 4$ superabsorbent hydrogel nanocomposite material. Molecules, 17: 9397-9412.

Shivay, Y.S., V. Pooniya, R. Prasad, M. Pal and R. Bansal (2016). Sulphur-coated urea as a source of sulphur and an enhanced efficiency of nitrogen fertilizer for spring wheat. Cer. Res. Com., 44: 513-523.
Snedecor, J.P., W. Cochran (1982)."Statistical methods" $7^{\mathrm{a}}$ ed. Aims, USA, The Iowa State University Press. 507 pp.

Soda, W., A.D. Noble, S. Suzuki, R. Simmons, L. Sindhusen and S. Bhuthorndharaj (2006). Co composting of acid waste bentonites and their effects on soil properties and crop biomass. J. Environ. Quality. 35: 2293-2301.

Suherman and D.D.Anggoro (2011). Producing slow release urea by coating with starch/acrylic acid in fluid bed spraying. Inter. J. Engin. \& Tech., 11: 77-80.

Suntari, R., R. Rurini and M. M. Soemarno. (2013). Study on the release of $\mathrm{N}$-available $\left(\mathrm{NH}^{+}\right.$and $\left.\mathrm{NO}^{-}\right)$of UreaHumate.Intern .J. Agri. and Fore., 6: 209-219.

Suntari, R., R. Retnowati, Soemarno and M. Munir (2015). Determination of urea-humic acid dosage of vertisols on the growth and production of rice. Agrivita 37: 185-192.

Taha, G. M. 1, S.A. Farahat, E.M. Elnggar and M. M. AL Molakab. (2016). Creation \& characterization of different coated urea materials \& their impact as controlled release fertilizers. J. Soil Sci., and Agric. Eng., Manso. Univ. 10: 793- 800.

Tan, K.H. (1991). "Principle of Soil Chemistry" (Dasar-dasar Kimia Tanah) (Alih bahasa: Didiek Hadjar Goenadi) Gadjah Mada University Press. Yogyakarta. P. 295

Tan, K.H. (1996). Soil sampling, preparation and analysis .Marcel dekker, Inc. New York, P.408

Vashishtha, M., P. Dongara and D. Singh, (2010). "Improvement in properties of urea by phosphogypsum coating" Int. J. Chemt. Rese., 2: 36- 44.

Virta, R. L. (2001). Clays: U.S. "Geological Survey Mineral Commodity Summaries" 2000.2 pp.

Wang, Y., C. Combe, and M.M. Clark. (2001). The effects of $\mathrm{pH}$ and calcium on the diffusion coefficient of humic acid. J. Membran Sci., 183: 49-60.

$\mathrm{Wu}, \mathrm{L}$. and M. Liu (2008). Preparation and properties of chitosan-coated NPK compound fertilizer with controlled-release and water-retention. Carbohydrate Polymers, 72: 240-247.

Zlatković, S. and L. Rašković (1998). The effect of the polyacrylamide, polyvinylalcohol and carboxymethylcellulose on the aggregation of the soil and on the growth of the plants. J. Environ. Prot., 1: $17-$ 23.

\section{خصائص وتجهيز يوريا بطيئة التحلل مغطاة بالبنتونيت والبولي أكريلاميد وهيومات البوتاسيوم كمركب سمادى والتى

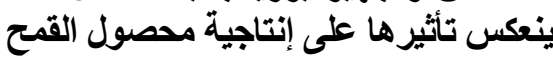 وجيدة زكريا حسن معهد بحوث الاراضى والمباه والبيئةـ مركز البحوث الزراعية ـ الجيزةـ مصر}

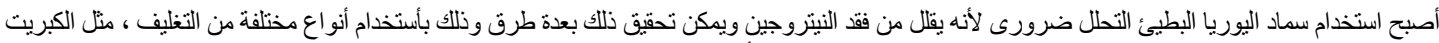

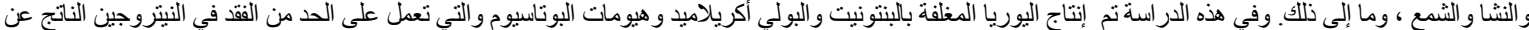

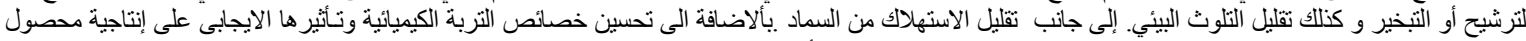

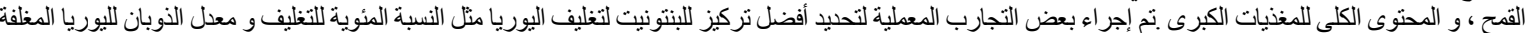

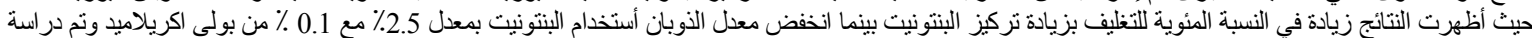

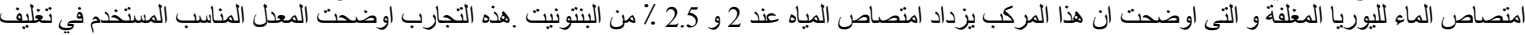

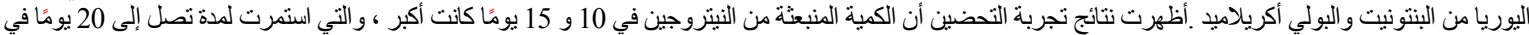

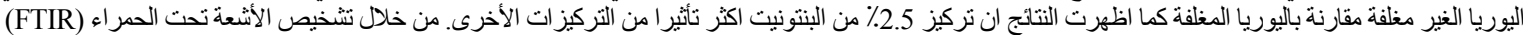

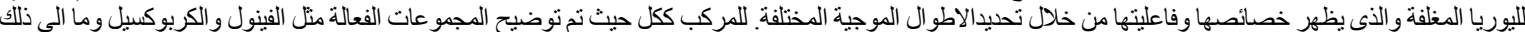

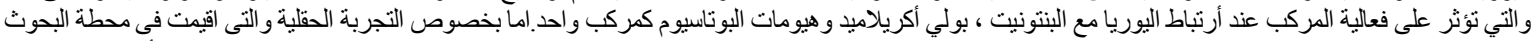

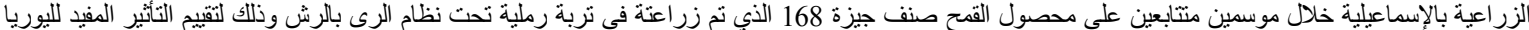

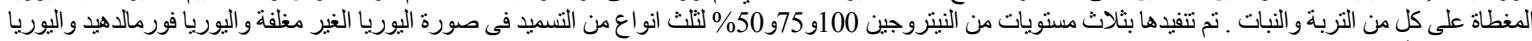

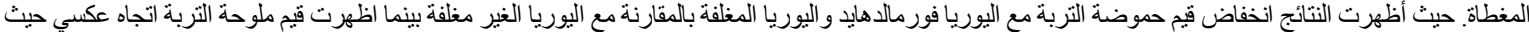

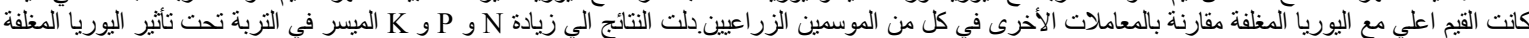

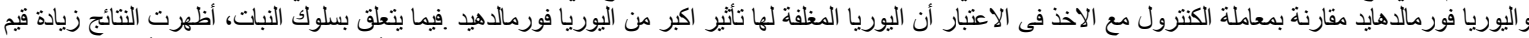

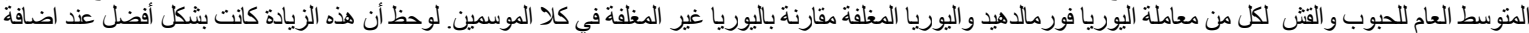

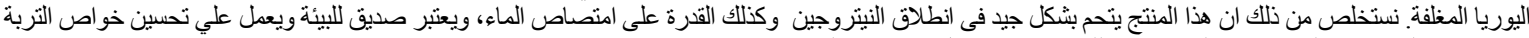

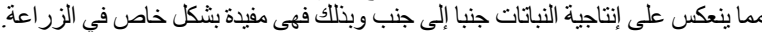

